\title{
Synthesis of Methyl Methacrylate From Coal-Derived Syngas
}

\author{
Quarterly Report \\ January 1 - March 31, 1998
}

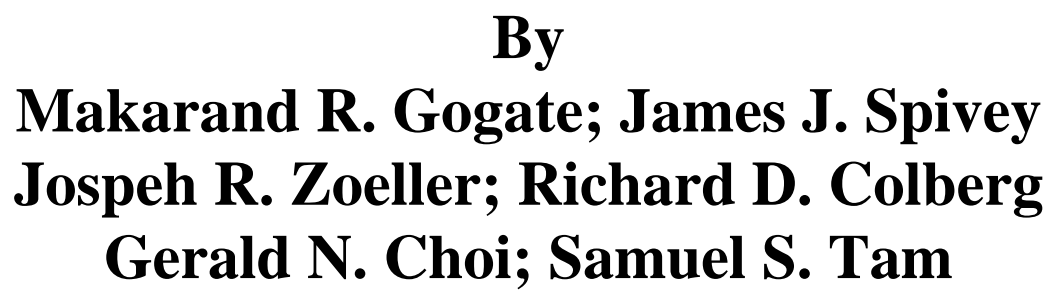

Work Performed Under Contract No.: DE-AC22-94PC94065

For

U.S. Department of Energy

Office of Fossil Energy

Federal Energy Technology Center

P.O. Box 880

Morgantown, West Virginia 26507-0880

By

Research Triangle Institute

3040 Cornwallis Road

P. O. Box 12194

Research Triangle Park, North Carolina 27709-2194 


\section{Disclaimer}

This report was prepared as an account of work sponsored by an agency of the United States Government. Neither the United States Government nor any agency thereof, nor any of their employees, makes any warranty, express or implied, or assumes any legal liability or responsibility for the accuracy, completeness, or usefulness of any information, apparatus, product, or process disclosed, or represents that its use would not infringe privately owned rights. Reference herein to any specific commercial product, process, or service by trade

name, trademark, manufacturer, or otherwise does not necessarily constitute or imply its endorsement, recommendation, or favoring by the United States Government or any agency thereof. The views and opinions of authors expressed herein do not necessarily state or reflect those of the United States Government or any agency thereof. 
Synthesis of Methyl Methacrylate from Coal-derived Syngas

Report Type:

QUARTERLY

Reporting Period Start Date:01/01/1998 End Date:03/31/1998

Principal Author(s): Makarand R. Gogate and James J. Spivey

Jospeh R. Zoeller and Richard D. Colberg

Gerald N. Choi

Samuel S. Tam

Report Issue Date: 04/17/1998

DOE Award No.: DE- AC22 -94PC94065 --15

Submitting

Organization(s)

Name \& Address
Research Triangle Institute

3040 Cornwallis Road P.O. Box 12194

(1)

RTP, NC 27709-2194

\section{Eastman Chemical Company \\ Kingsport, TN 37662-5150}

(2)

\section{Bechtel}

San Francisco, CA 94119-3965

(3)

Bechtel

Houston, TX 77252-2166 


\begin{abstract}
Research Triangle Institute (RTI), Eastman Chemical Company, and Bechtel collectively are developing a novel three-step process for the synthesis of methyl methacrylate (MMA) from coalderived syngas that consists of the steps of synthesis of a propionate, its condensation with formaldehyde to form methacrylic acid (MAA), and esterification of MAA with methanol to produce MMA. RTI has completed the research on the three-step methanol-based route to MMA. Under an extension to the original contract, RTI is currently evaluating a new DMEbased process for MMA. The key research need for DME route is to develop catalysts for DME partial oxidation reactions and DME condensation reactions.

Over the last month, RTI has finalized the design of a fixed-bed microreactor system for DME partial oxidation reactions. RTI incorporated some design changes to the feed blending system, so as to be able to blend varying proportions of DME and oxygen. RTI has also examined the flammability limits of DME-air mixtures. Since the lower flammability limit of DME in air is 3.6 volume percent, RTI will use a nominal feed composition of 1.6 percent in air, which is less than half the lower explosion limit for DME-air mixtures. This nominal feed composition is thus considered operationally safe, for DME partial oxidation reactions. RTI is also currently developing an analytical system for DME partial oxidation reaction system.
\end{abstract}




\section{TABLE OF CONTENTS}

\section{Page}

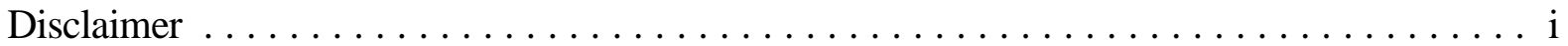

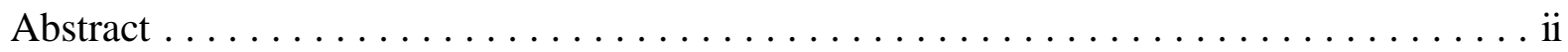

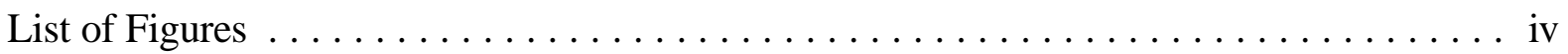

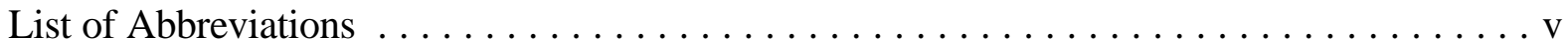

Executive Summary $\ldots \ldots \ldots \ldots \ldots \ldots \ldots \ldots \ldots \ldots \ldots \ldots \ldots \ldots$

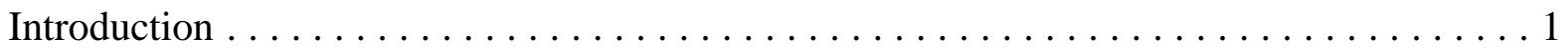

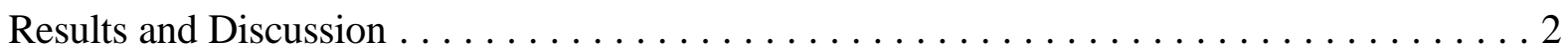

Task 1. Propionate Synthesis (Eastman and Bechtel) $\ldots \ldots \ldots \ldots \ldots \ldots \ldots$

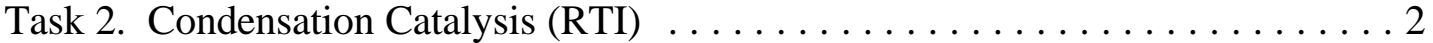

Task 3. Slurry Reactor Studies (RTI and Eastman) $\ldots \ldots \ldots \ldots \ldots \ldots \ldots$

Task 4. DME Feedstock Evaluation (RTI and Eastman) $\ldots \ldots \ldots \ldots \ldots \ldots$

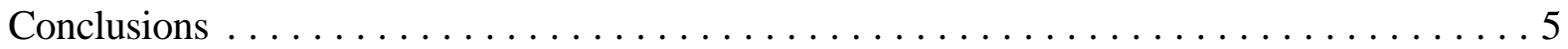

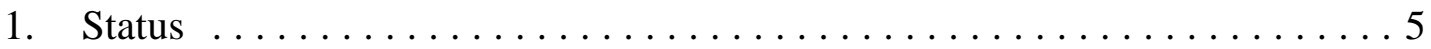

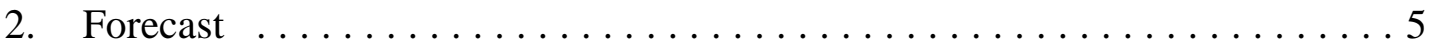

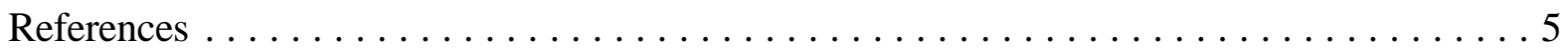




\section{LIST OF FIGURES}

Number

Page

1 The RTI-Eastman-Bechtel three-step MMA process (with external

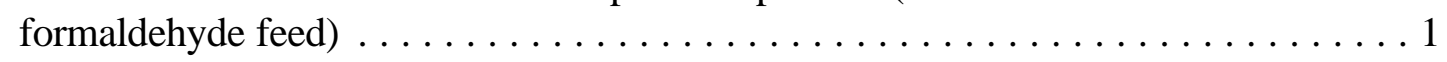

2 Flammability limits for DME-carbon dioxide-air mixtures $\ldots \ldots \ldots \ldots \ldots \ldots$

3 Flammability limits for DME-nitrogen-air mixtures $\ldots \ldots \ldots \ldots \ldots \ldots \ldots$

4 Proposed fixed-bed microreactor system for DME feedstock studies . . . . . . . . 5

5 Fixed-bed microreactor system for DME partial oxidation system incorporating a

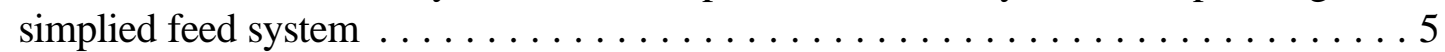




\section{LIST OF ABBREVIATIONS}

$\mathrm{ACH}$

DME

DOE

ESCA

$\mathrm{HCHO}$

LFL

MAA

MMA

MP

$\mathrm{O}_{2}$

$\mathrm{WO}_{3}$

XRD

XPS
Acetone cyanohydrin

Dimethyl ether

U.S. Department of Energy

Electron spectroscopy for chemical analysis

Formaldehyde

Lower flammability limit

Methacrylic acid

Methyl methacrylate

Methyl propionate

Oxygen

Tungsten oxide

X-ray diffraction

$\mathrm{X}$-ray photoelectron spectroscopy 


\section{EXECUTIVE SUMMARY}

The Research Triangle Institute (RTI)-Eastman-Bechtel team is developing a novel process for the synthesis of methyl methacrylate (MMA) from coal-derived syngas. The three-step process consists of synthesis of a propionate, its condensation with formaldehyde to produce methacrylic acid (MAA), and esterification with methanol to yield MMA. As an extension to the original contract, RTI is currently working on the evaluation of a dimethyl ether (DME)-based process. In this evaluation, DME is used as a source of formaldehdye, and methyl propionate (MP) is used as the propionyl source. The key research need for a DME-based process is to develop catalysts for DME partial oxidation reactions and DME condensation reactions.

Over the last month, RTI has finalized the design of a fixed-bed microreactor system for DME partial oxidation reactions. The final design incorporated several changes and made the feed blending system simpler. RTI has also examined the flammability limits of DME/oxygen and DME/air mixtures. Since the lower flammability limit of DME is 3.6 volume percent, RTI will use a feed comprising nominally of 1.6 volume percent DME in air, which is less than half the lower explosive limit for DME, and is thus operationally safe. RTI is currently modifying its analytical system for use with partial oxidation reactions. 


\section{INTRODUCTION}

The most widely practiced commercial technology for the synthesis of methacrylic acid (MAA) and methyl methacrylate (MMA) is the acetone cyanohydrin $(\mathrm{ACH})$ process. The $\mathrm{ACH}$ process requires handling of large quantities of extremely toxic and hazardous hydrogen cyanide and generates copious amounts of ammonium sulfate wastes that are either discarded or reclaimed at substantial cost. The ACH technology is currently environmentally and economically untenable for any new expansions, primarily because of the cost of either disposing or regenerating the bisulfate waste.

There is a strong drive within the chemical industry for a replacement process for MMA synthesis (Spivey et al., 1995, 1996a, 1996b). The Research Triangle Institute (RTI)-Eastman-Bechtel research team is developing a novel three-step process for synthesis of methyl methacrylate from

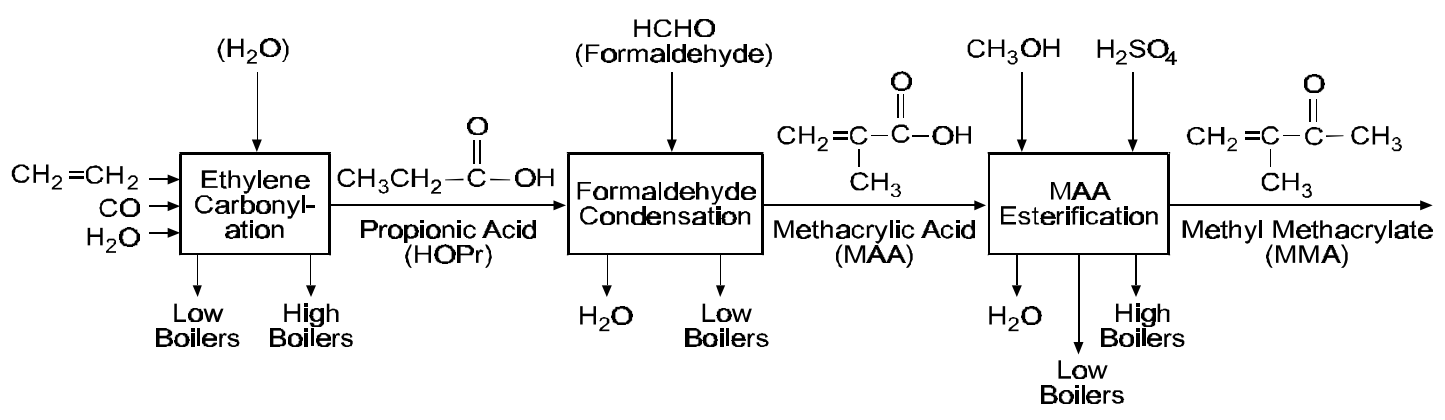

Figure 1. The RTI-Eastman-Bechtel three-step MMA process (with external formaldehyde feed).

coal-derived syngas. This three-step process is shown schematically in Figure 1. In this process for MMA manufacture, Steps 1 (ethylene carbonylation) and 2 (formaldehyde condensation), present challenges for successful commercial demonstration of the process. Step 3 (MAA esterification) is a known art.

The three-step methanol route has been investigated by the RTI-Eastman-Bechtel research team. For investigation purposes, the scope of work was divided into three tasks. Task 1 focused on the synthesis of a propionate from ethylene, $\mathrm{CO}$, and steam, Task 2 focused on the condensation of the propionate with formaldehyde, and Task 3 focused on the one-step oxidative condensation in a slurry reactor. Due to a promising economic evaluation of the three-step process, where propionate synthesis, condensation, and esterification are carried out in separate reactors, the development of one-step MMA process in a slurry reactor (Task 3), was de-emphasized, for now. Upon conclusion of the original contract, the RTI-Eastman-Bechtel research team undertook the development of a DME-based process to MMA, as an extension to the three tasks of the original contract. This add-on task was called as Task 4, and termed as DME feedstock evaluation.

Under this extension, the RTI-Eastman-Bechtel research team is studying the use of DME, instead of methanol, to generate formaldehyde, either externally or in situ. Methyl propionate (MP) is used as the propionyl source, instead of PA. The DME-based route can produce MMA in one step, and is possibly a cost-effective alternative to the methanol-based route. 


\section{RESULTS AND DISCUSSION}

\section{Task 1. Propionate Synthesis (Eastman and Bechtel)}

Eastman has completed the experimental work and economic analysis for the overall process, and have completed their responsibilities per the statement of work for the original contract.

\section{Task 2. Condensation Catalysis (RTI)}

The catalyst development effort at RTI for condensation of formaldehyde with propionic acid included a screening of over 81 potential catalysts (Spivey et al., 1998; Spivey et al., 1997a, 1997b, 1996a, 1996b; Gogate et al., 1997), and as a result, Group V metals including vanadium, niobium, and tantalum have been shown to be active, selective, and relatively stable condensation catalysts. The performance of a 20 -percent $\mathrm{Nb} / \mathrm{SiO}_{2}$ catalyst, in terms of $\mathrm{HCHO}$ and PA conversions and MAA selectivity, at operating conditions of $300{ }^{\circ} \mathrm{C}, 2 \mathrm{~atm}$, mole flow rates of PA:HCHO: $\mathrm{N}_{2}=72: 16: 220 \mathrm{mmol} / \mathrm{h}, 5-\mathrm{g}$ (16-30 mesh size) catalyst charge, and a volume hourly space velocity of $1,080 \mathrm{~cm}^{3} / \mathrm{g}$ cat $\cdot \mathrm{h}$ is the most superior, among the catalysts tested.

Over the last month, RTI has continued with follow-on characterization work on a 10-percent $\mathrm{Nb} / \mathrm{Si}$ condensation catalyst, which was subjected to a long-term reaction-regeneration cycle study. In particular, RTI is analyzing the deactivated catalyst by BET- $\mathrm{N}_{2}$ surface area, pore volume, XPS/ESCA, XRD, and ICP-MS to evaluate the causes of catalyst deactivation. The XPS/ESCA studies will be carried out at Eastman, and will measure the reduction in crystallite size of niobium, as a result of multiple reaction-regeneration cycles.

\section{Task 3. Slurry Reactor Studies (RTI and Eastman)}

Based on Eastman's economic analysis (presented in annual technical report for FY 1997), the route. The slurry reactor technology will likely be revisited at the end of the dimethyl ether (DME) extension of this contract (slated for completion on March 31, 1999).

\section{Task 4. DME Feedstock Evaluation (RTI and Eastman)}

RTI has initiated the research on the DME route and completed the design of a fixed-bed microreactor system for DME partial oxidation reactions. RTI has evaluated the flammability limits for DME-air mixtures. The charts have been given in Figures 2 and 3. Since the lower flammability limit (LFL) for DME in air is 3.6 volume percent, RTI will use DME-air feed mixtures of compositions nominally not exceeding 1.6 volume percent DME, which is less than half the LFL. For additional safety, RTI will obtain DME-nitrogen mixtures, and blend those inhouse with oxygen or air, as necessary, to attain the required feed compositions. The schematic of the original fixed-bed microreactor system for DME partial oxidation and a modifed reactor design that incorporates a simpler feed blending system has been given in Figures 4 and 5. RTI is also working on catalyst synthesis for DME partial oxidation reactions. Initial catalysts for DME partial oxidation studies will be based on tungsten oxide $\left(\mathrm{WO}_{3}\right)$ supported on silica, based on literature results. 


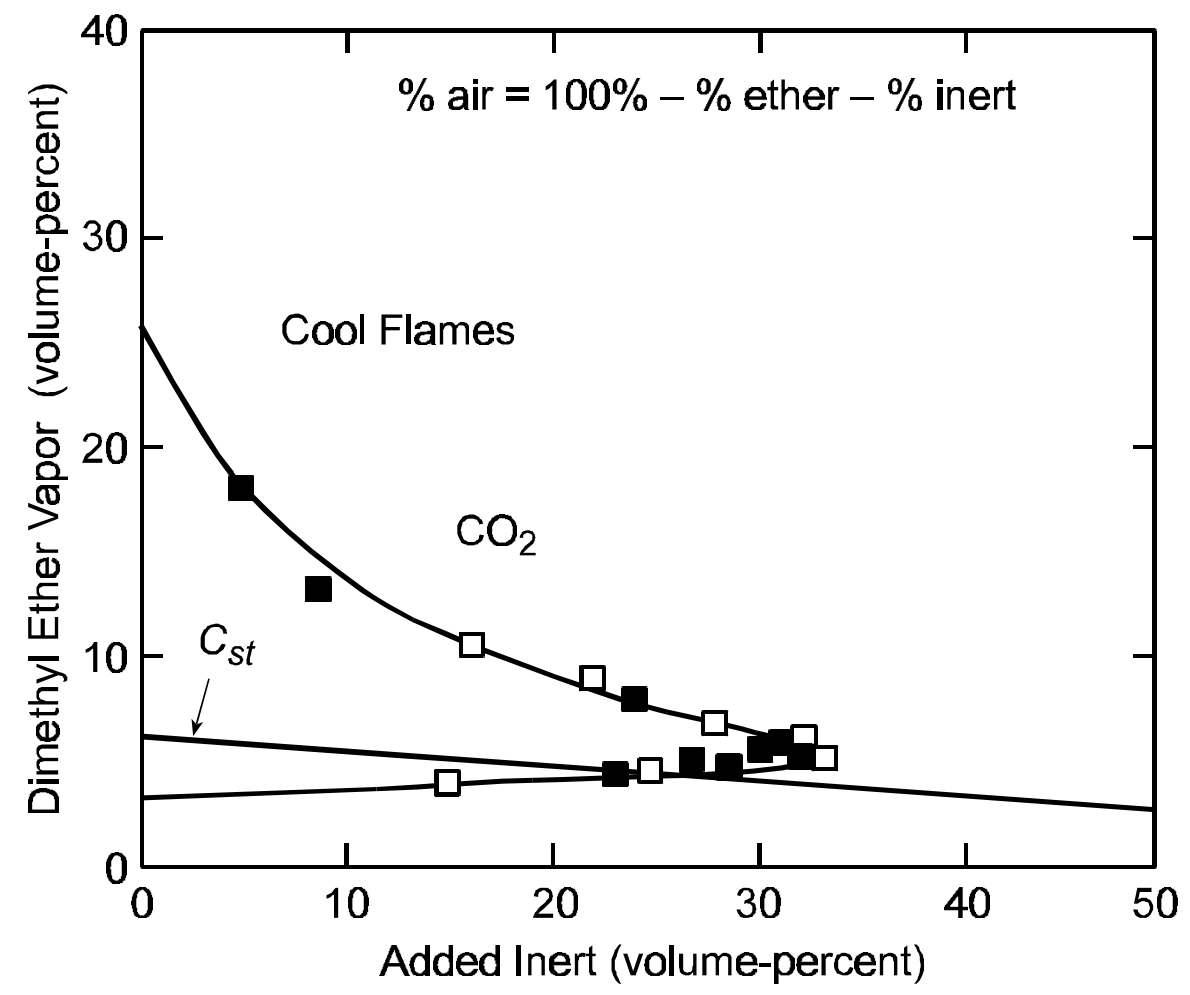

Figure 2. Flammability limits for DME-carbon dioxide-air mixtures

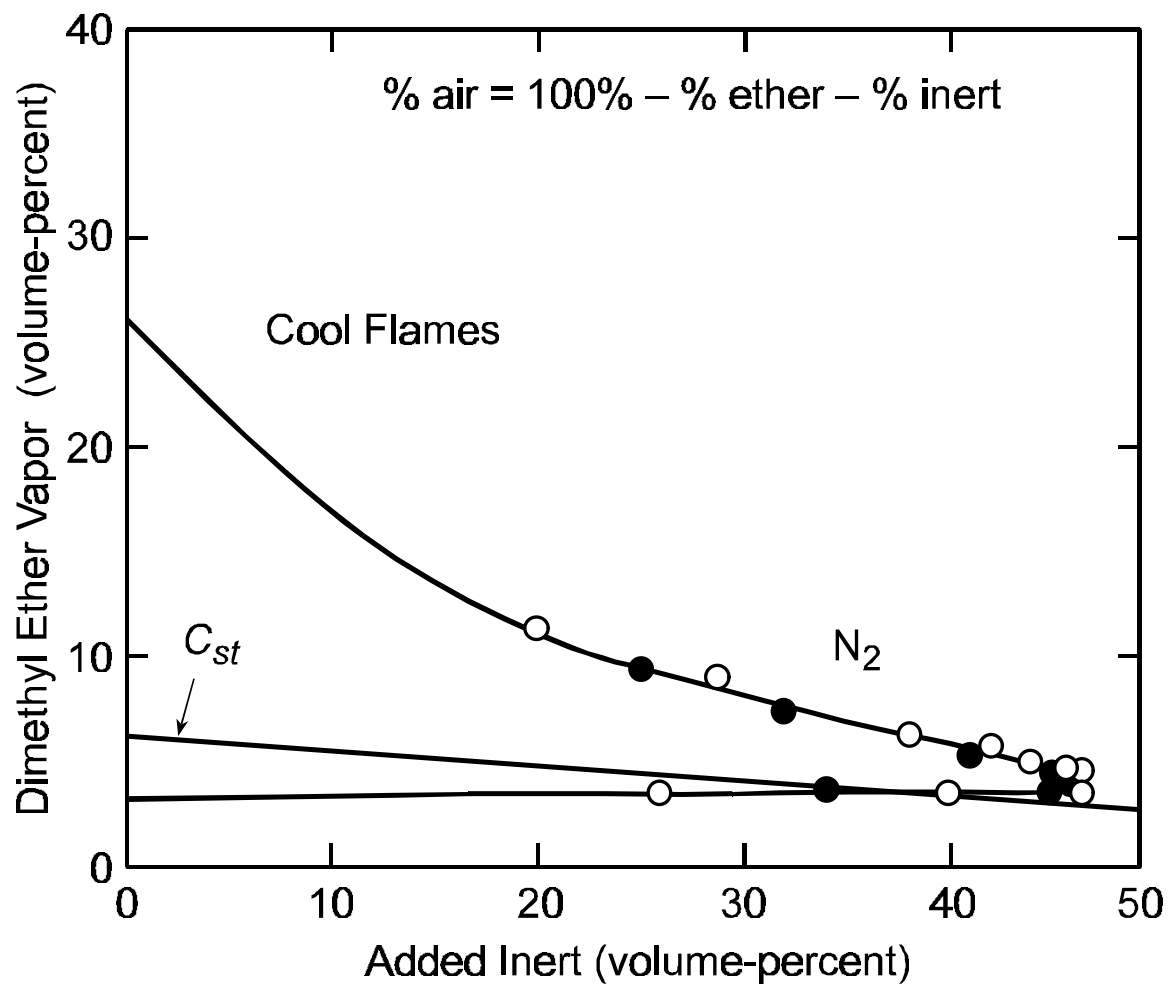

Figure 3. Flammability limits for DME-nitrogen-air mixtures 


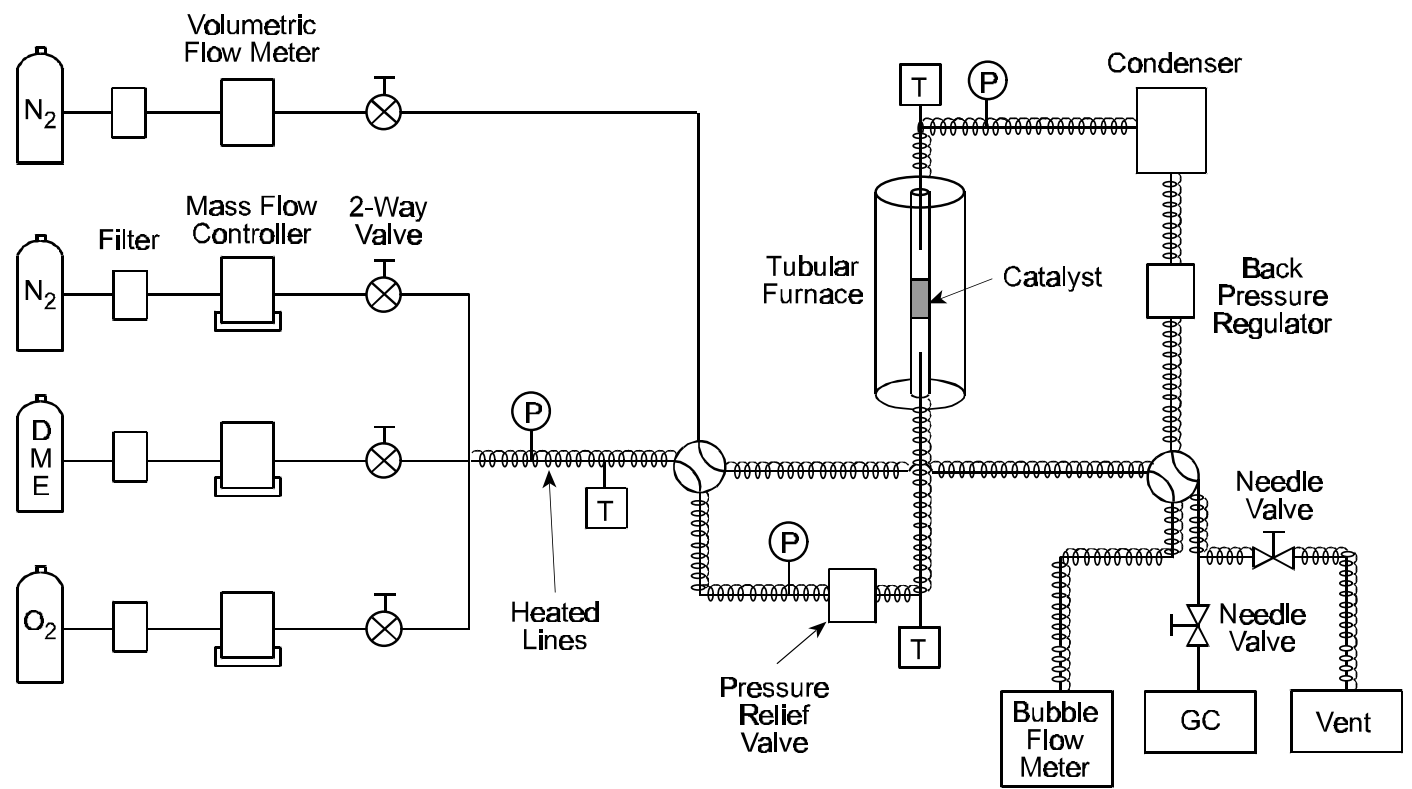

Figure 4. Proposed fixed-bed microreactor system for DME feedstock studies.

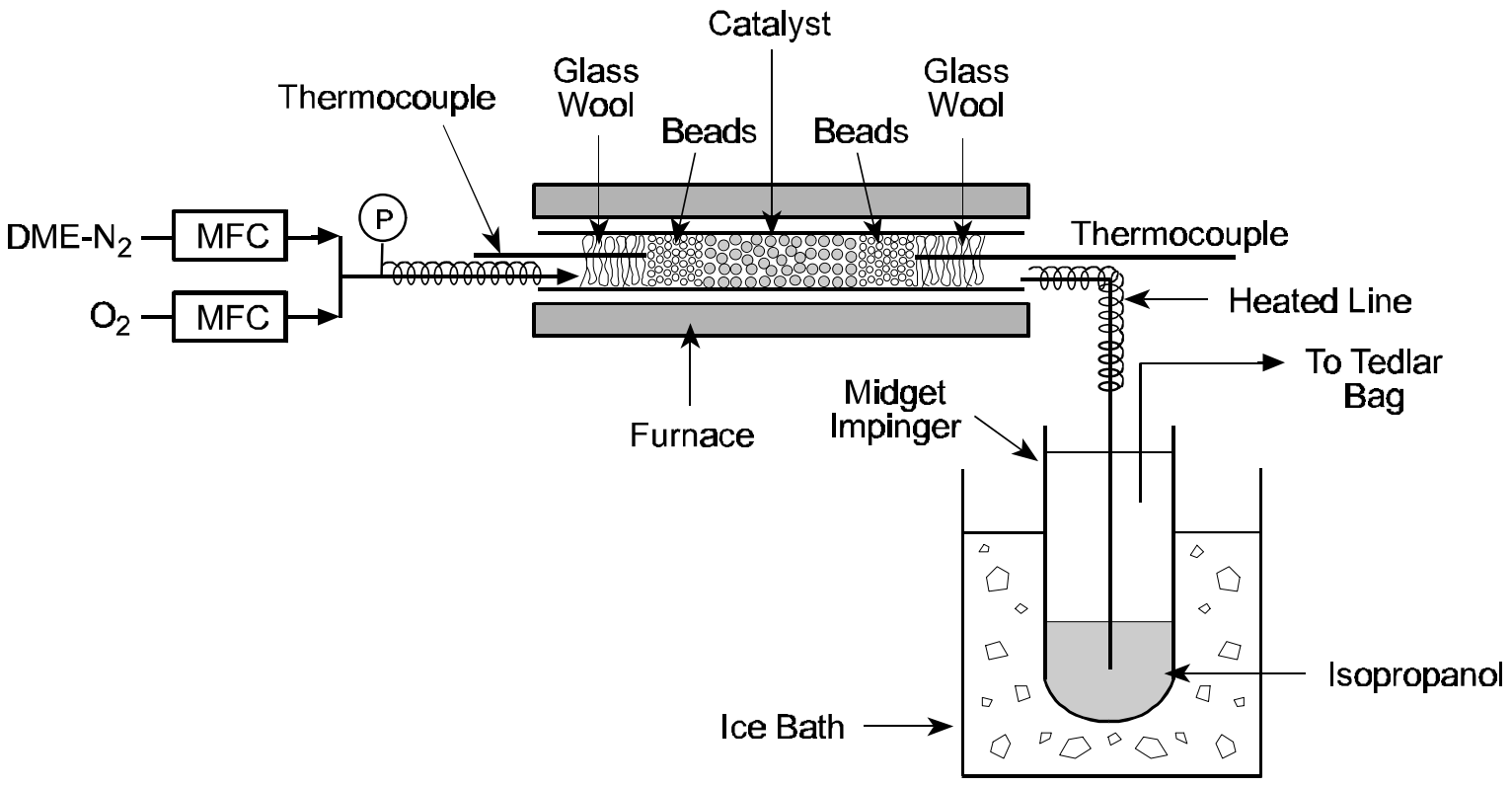

Figure 5. Fixed-bed microreactor system for DME partial oxidation system incorporating a simplied feed system 


\section{CONCLUSIONS}

\section{Status}

Task 1 (Propionate Synthesis) and Task 2 (Condensation Catalysis) are complete. Task 3 (Slurry Reactor Studies) is on hold and will likely be revisited during the DME extension or upon its completion. In Task 4 (DME Feedstock Evaluation), RTI has designed, assembled, and operated a fixed-bed microreactor system for DME partial oxidation reactions. The feed blending system for this reactor system was also modified, so as to be able to blend varying proportions of DME and oxygen. RTI has also begun the development of an analytical system, for DME studies. RTI has also studied the flammability limits for DME-air mixtures. Since the lower flammability limit (LFL) for DME is 3.6 volume percent in air, RTI will use feed compositions of ca. 1.6 volume percent DME in air, which is less than half the LFL for DME.

\section{Forecast}

In the original contract, RTI will carry out follow-on work focused on the following two tasks:

- Characterization of the used $10 \% \mathrm{Nb} / \mathrm{Si}$ catalyst, from the reaction-regeneration cycle study, to elucidate the causes for catalyst deactivation.

- Reaction kinetics for vapor phase condensation reaction of formaldehyde and propionic acid, including reaction orders in formaldehyde, propionic acid, and activation energy of the reaction.

These two tasks are important in refining certain assumptions made in the preliminary economic analysis of the RTI-Eastman-Bechtel three-step process.

Current research on Task 4 (DME Feedstock Evaluation) will focus on:

- DME partial oxidation studies, initially with externally generated formaldehyde, to evaluate several different catalyst systems for these reactions.

\section{REFERENCES}

Gogate, M.R., J.J. Spivey, J.R. Zoeller. 1997. "Synthesis of methyl methacrylate by vapor phase condensation of formaldehyde with propionate derivatives," Catal. Today, 36(3), pp. 243254.

Spivey, J.J., M.R. Gogate, J.R. Zoeller, G.C. Tustin. 1998. U.S. Patent 5,710,328, "Synthesis of $\alpha$-, $\beta$-unsaturated carboxylic acids and anhydrides," January 20.

Spivey, J.J., M. R. Gogate, J.R. Zoeller, R.D. Colberg. 1997a. "Novel Catalysts for Environmentally Friendly Synthesis of Methyl Methacrylate," Ind. Eng. Chem. Res., 36(11), pp. 4600-4608. 
Spivey, J.J., M.R. Gogate, J.R. Zoeller, R.D. Colberg, S.S. Tam, G.N. Choi. 1997b.

"Environmentally Friendly Synthesis of Methyl Methacrylate from Coal-derived Syngas," in Proceedings of International Chemical Congress - Fifth Chemical Congress of North America, Cancun, Mexico.

Spivey, J.J., M.R. Gogate, J.R. Zoeller, R.D. Colberg, S.S. Tam, and G.N. Choi. 1996a. "Synthesis of Methyl Methacrylate from Coal-derived Syngas," In Proceedings of the First Joint Power and Fuel Systems Contractors' Conference, U.S. DOE/PETC, Pittsburgh, PA, July 9-11.

Spivey, J.J., M.R. Gogate, J.R. Zoeller, R.D. Colberg, G.N. Choi, S.S. Tam, R.E. Tischer, R.D. Srivastava. 1996b. "Novel Syngas-based Process for Methyl Methacrylate," in Proceedings of the Thirteenth Annual International Pittsburgh Coal Conference, Volume 1, pp. 559-564, The University of Pittsburgh, Pittsburgh, PA.

Spivey, J.J., M.R. Gogate, E.D. Middlemas, J.R. Zoeller, S.S. Tam, G.N. Choi, R.E. Tischer, R.D. Srivastava. 1995. "A New Route to Acrylates and Methacrylates from Syngas," In Proceedings of the World Environmental Congress, London, Ontario, September 17-22. 